\title{
Traumatic intracerebral infarction due to vertebral and carotid artery dissection
}

\author{
Prasad Ellanti, Conor Hurson
}

Department of Trauma and Orthopaedics, St. Vincents University Hospital, Dublin, Ireland

\section{Correspondence to} Dr Prasad Ellanti, prasad.ellanti@gmail.com

Accepted 6 December 2014

\section{DESCRIPTION}

A 38-year-old woman presented to the emergency department subsequent to a high-velocity single vehicle road traffic accident with a fracture of left ulna and radius, right clavicle and sacrum. There was no history of loss of consciousness. Her Glasgow Coma Scale on presentation was 13 and quickly improved to 15 . An initial CT brain was normal. On day 4 postadmission she developed rapidly progressive weakness to all four limbs with upper motor signs. An emergent CT brain revealed extensive areas of cerebral infarction bilaterally (figure 1A, B) with an evolving hydrocephalus. A $\mathrm{CT}$ angiogram revealed a left internal carotid artery dissection (figure 2B between 2 arrows) and a right vertebral artery dissection (figure $2 \mathrm{~A}$ The dashed arrow marks the point where the missing right vertebral artery (dashed lines) should join the left vertebral artery to form the basilar artery). An extraventricular drain was sited by the neurosurgeons emergently. She was discharged 9 weeks later mobilising on a Zimmer frame having recovered near complete motor function and a hemianopia on the left.

The incidence of traumatic dissection is thought to be between 2 to $5 / 1000$ with up to $50 \%$ having permanent neurological deficits. Those with extracranial dissections can develop a stroke within $24 \mathrm{~h}$ but some can occur up to 7 days later. Anyone with a neurological deficit that is inconsistent with their injuries or with the initial CT brain should be investigated. Trauma patients at a high risk for dissection include those with blunt trauma to the head or neck, cervical or facial bone fractures, those with ischaemic changes on initial CT or the presence of a carotid bruit. ${ }^{1}{ }^{2}$ Treatment varies with each patient but is primarily medical with anticoagulation and antiplatelet therapy. Anticoagulation is associated with a high risk of intracranial bleeding. Endovascular stenting is an option for those who are unsuitable for medical treatment. ${ }^{12}$

\section{Learning points}

Patients with an extracranial dissection can develop the symptoms of a stroke within $24 \mathrm{~h}$ of the injury, however, some may develop symptoms up to 7 days later.

- Those with blunt trauma to the head or neck, cervical or facial bone fractures, those with ischaemic changes on initial $\mathrm{CT}$ or the presence of a carotid bruit are at risk of dissection.

- Close monitoring, early recognition and prompt treatment confer better outcomes in what is otherwise a devastating scenario with high risk of morbidity and mortality.
CrossMark

To cite: Ellanti P, Hurson C. BMJ Case Rep Published online: [please include Day Month Year] doi:10.1136/ bcr-2014-207286
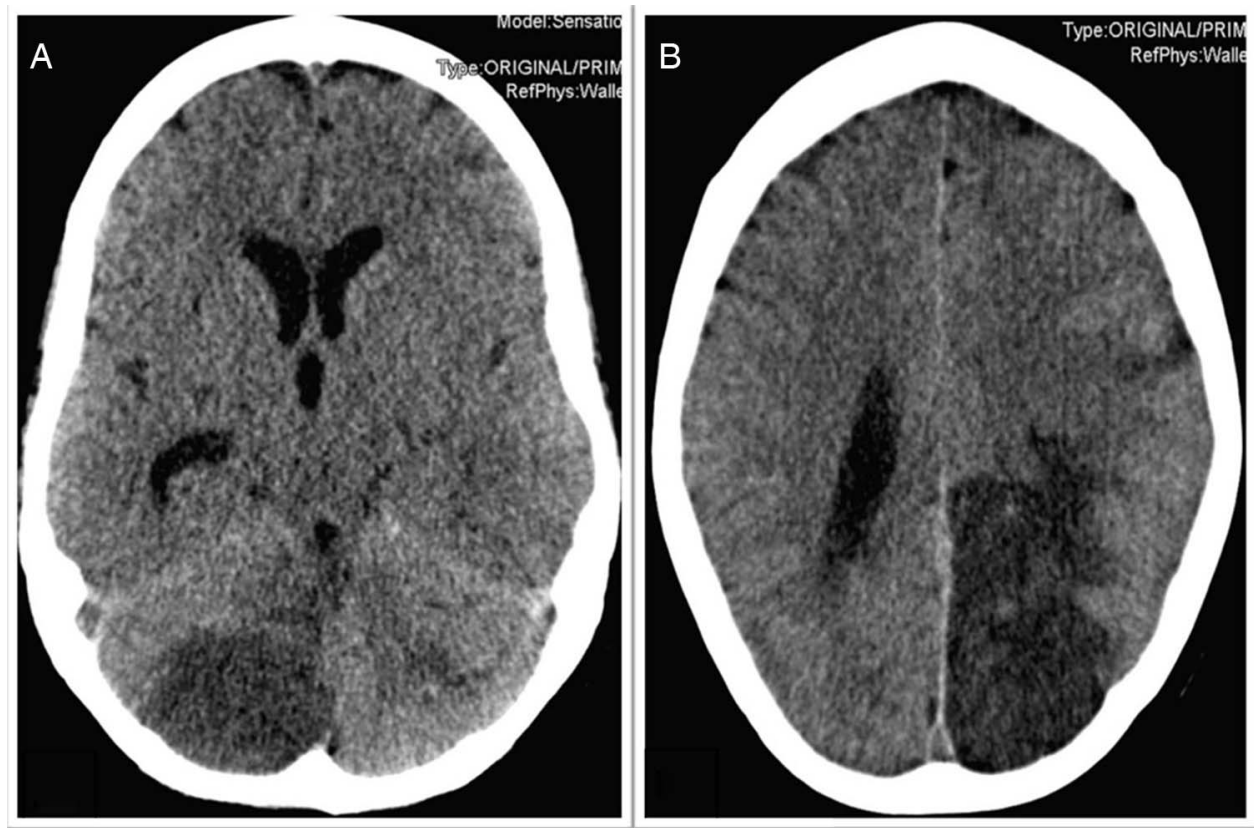

Figure 1 (A and B) CT brain demonstrating extensive areas of cerebral infarction bilaterally with an evolving hydrocephalus. 

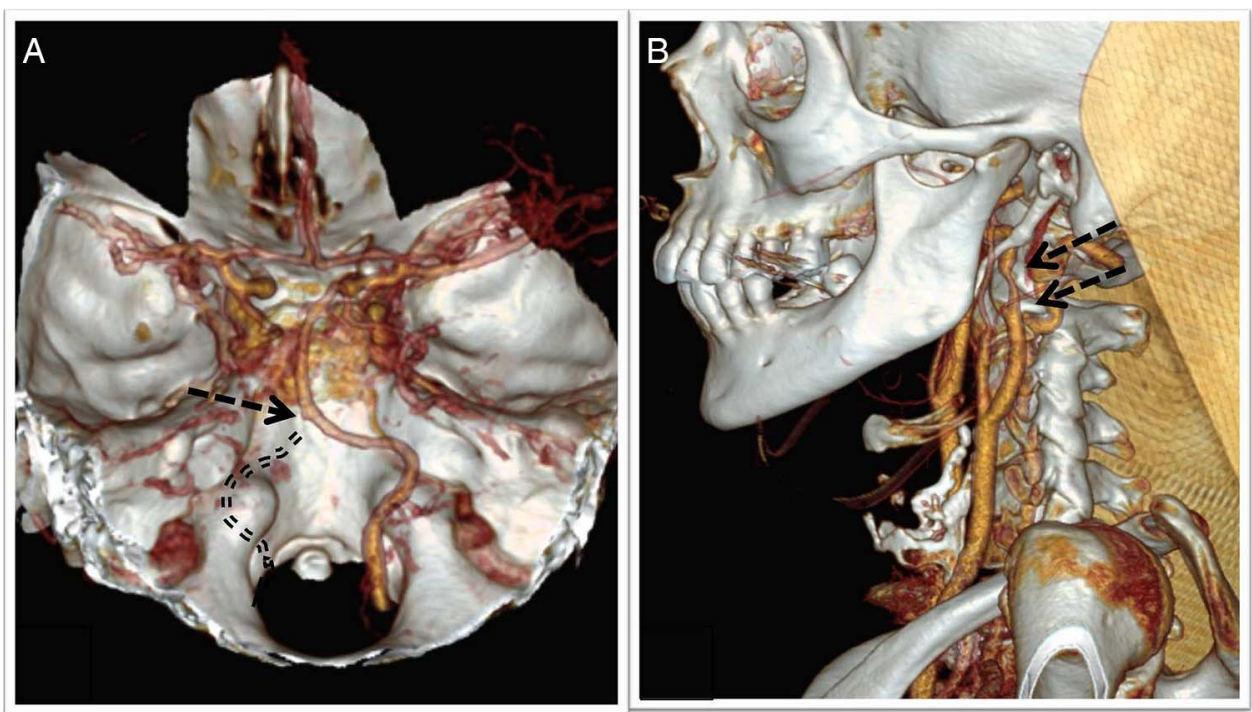

Figure 2 (A) CT angiogram demonstrating a right vertebral artery dissection (The dashed arrow marks the point where the missing right vertebral artery (dashed lines) should join the left vertebral artery to form the basilar artery). (B) CT angiogram demonstrating a left internal carotid artery dissection (between 2 arrows).

\section{Competing interests None.}

\section{Patient consent Obtained.}

Provenance and peer review Not commissioned; externally peer reviewed.

\section{REFERENCES}

1 Biffl WL, Cothren CC, Moore EE, et al. Western Trauma Association critical decisions in trauma: screening for and treatment of blunt cerebrovascular injuries. $J$ Trauma 2009;67:1150-3.

2 Bromberg WJ, Collier BC, Diebel LN, et al. Blunt cerebrovascular injury practice management guidelines: the Eastern Association for the Surgery of Trauma. J Trauma 2010;68:471-7.

Copyright 2014 BMJ Publishing Group. All rights reserved. For permission to reuse any of this content visit http://group.bmj.com/group/rights-licensing/permissions.

BMJ Case Report Fellows may re-use this article for personal use and teaching without any further permission.

Become a Fellow of BMJ Case Reports today and you can:

- Submit as many cases as you like

- Enjoy fast sympathetic peer review and rapid publication of accepted articles

- Access all the published articles

- Re-use any of the published material for personal use and teaching without further permission

For information on Institutional Fellowships contact consortiasales@bmjgroup.com

Visit casereports.bmj.com for more articles like this and to become a Fellow 